\title{
Needed investments in the power system to bring wind energy to shore in Belgium
}

\author{
Patrik Buijs GSM, IEEE, David Bekaert, GSM, IEEE, Dirk Van Hertem, IEEE, Ronnie Belmans fellow, IEEE \\ ESAT-ELECTA, Katholieke Universiteit Leuven \\ Kasteelpark Arenberg 10, PB2445, 3001 Heverlee, Belgium \\ Tel: (+32) 16 321020, fax: (+32) 16321985 \\ e-mail: ronnie.belmans@esat.kuleuven.be
}

\begin{abstract}
Renewable energy sources, and especially wind, take an increasing fraction of the European electric energy generation and they form an important part of the plans of the European commission towards a more sustainable future. Also for Belgium, wind power offers the most important renewable energy potential. Especially offshore wind power projects are booming and more than $2 \mathrm{GW}$ is announced to be installed in the Belgian coastal waters. Of course, this energy needs to be transported to the mainland. At this moment however, the power system near to the coast is not ready to absorb such large amounts of electric power. New investments in transmission lines will be needed but these have been difficult in the densely populated country and further public opposition out of social, environmental and political concern is expected.

For this paper, the Belgian situation is examined considering different investment options. A novel optimal investment model based on [1] is used to determine the techno-economic optimal investment policy. Strong emphasis is placed on retaining the current right-of-way.
\end{abstract}

Index Terms-Transmission investments, Offshore wind power

\section{INTRODUCTION}

\section{A. Wind power production in Belgium}

Since the early nineties, the worldwide installed wind power capacity has been increasing exponentially, with over $90 \mathrm{GW}$ installed in 2007. $56 \mathrm{GW}$, or more than $60 \%$, is installed in EU-25. [2] It is clear that the two major contributors of wind energy in Europe are Germany ( $>22 \mathrm{GW}$ ) and Spain $(>15 \mathrm{GW})$. With only $0.3 \mathrm{GW}$ installed, Belgium has been lagging behind in its efforts to incorporate wind power in the power system. There are various reasons, mainly less favorable incentives and limited open spaces in the densely populated country. The recent evolutions in offshore wind technology and the regulatory support by means of certificates has given a boost to new projects in the Belgian coastal waters of the North Sea. Table I and figure 1 show the projected wind farms in the North sea. While the first $300 \mathrm{MW}$ project by C-power is still under construction, virtually the entire zone where wind power parks are allowed has been applied for concession for a total of seven smaller projects. For some zones there are even multiple requests for a single concession. It is up to the federal regulator (CREG) to assign these last concessions. After that, each project needs to obtain the necessary permits (environmental, building,...) from both the federal institutions (the sea is federal jurisdiction) as the Flemish institutions (the onshore connection will happen in Flanders). For the C-Power project, this permitting process took a total of 3.5 years. It is therefore not unreasonable to estimate that by 2020 more than $2 \mathrm{GW}$ of wind will be installed in the Belgian coastal waters.

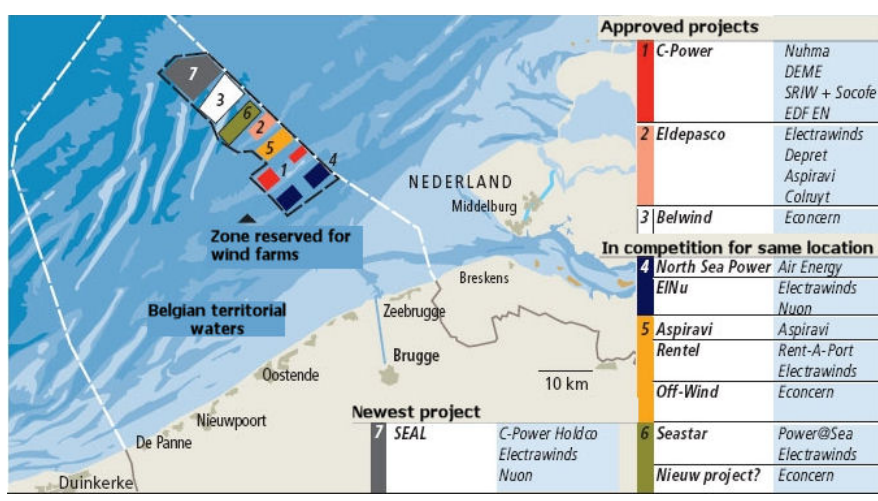

Fig. 1. Location of planned Belgian offshore windfarms (source: De Tijd, $31 / 07 / 2008$

TABLE I

PLANNED AND CONSIDERED WIND FARMS IN BELGIUM

\begin{tabular}{lcccccc}
\hline Name & $\begin{array}{c}\text { Power } \\
\text { MW }\end{array}$ & $\begin{array}{c}\text { Distance } \\
\text { km }\end{array}$ & Date & Concession & Permit & Area \\
\hline C-Power & 300 & 28 & 2009 & yes & yes & 1 \\
Eldepasco & 216 & 35 & & yes & no & 2 \\
Belwind & 330 & 46 & & yes & no & 3 \\
Other & $1200 ?$ & & & no & no & $4-7$ \\
\hline
\end{tabular}

It is important to mention that the possible location of wind farms in Belgian coastal waters is limited to a small area for different reasons such as the existence of shipping routes, naval exercise areas, pipes and cables, sand reclamation, nature reserves,....

The region closest to shore where offshore wind turbines are allowed is located nearly $30 \mathrm{~km}$ from the coast (figure 1).

\section{B. The Belgian power system}

The Belgian power system forms an important part of the highly meshed UCTE synchronous zone which covers most of continental Europe. The system has strong $380 \mathrm{kV}$ ties with both the Netherlands and France. The minimum load is about $6.4 \mathrm{GW}$ during summer nights and the maximum load is around $14 \mathrm{GW}$ during the winter peak, with an average of about $10 \mathrm{GW}$. The main load centers are in the center of the country, the so called ABC axis (Antwerp - Brussels Charleroi) and in the Liège area in the east of Belgium. These areas are well connected with both $380 \mathrm{kV}$ and $150 \mathrm{kV}$ lines. As can be seen from figure 2, the coastal area in the west of Belgium is only connected with $150 \mathrm{kV}$ lines as there are no major load centers there, and up to now there is also no reason 


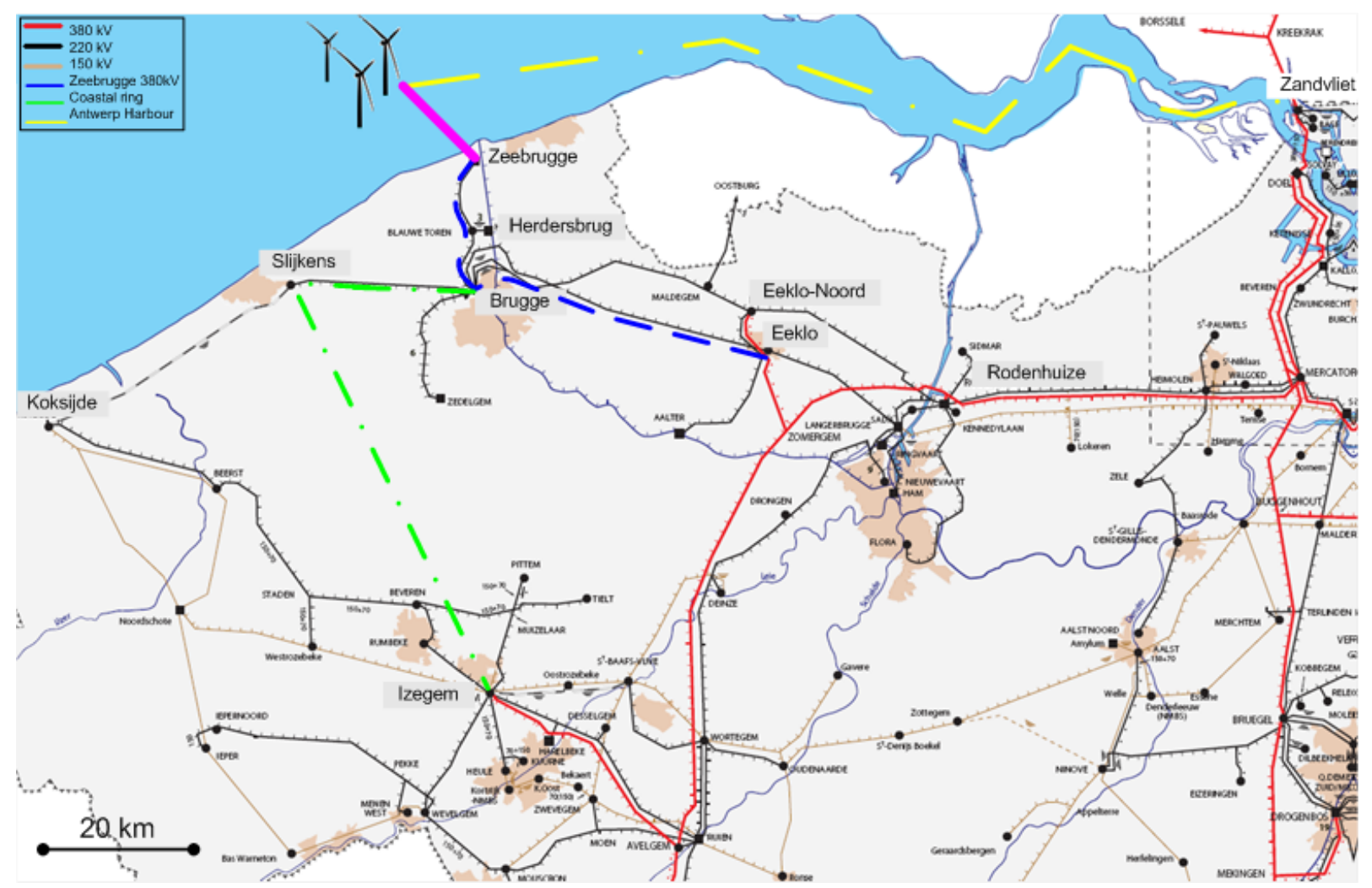

Fig. 2. The Belgian coastal grid area (source: Elia) and possible grid extensions, see Section IV

for major transport of energy from or to the coast. A typical single circuit $150 \mathrm{kV}$ power line can carry about $155 \mathrm{MVA}$ of electrical power, a double circuit installation about 310 MVA. The power plant of Herdersbrug (460 MW) (indicated on the map) causes a flow that is already going from the coast to the center. Additional generation from offshore wind farms would add to these existing flows, quickly filling these lines up to their rating. Earlier studies have indicated that 600 to $900 \mathrm{MW}$ of additional transport capacity could be achieved with only minor changes to the existing transmission system (no new lines needed). [3] The foreseen wind power generation in the North Sea clearly exceeds the available transmission capacity.

\section{Connection points}

The connection from the wind farm to the transmission system is a vital element of wind farm construction. As the planned wind farms all are larger than $200 \mathrm{MW}$, the most appropriate voltage level for the connections is $150 \mathrm{kV}$ or possibly even higher. Not only are the cable connections technically challenging, especially on these high voltage levels, they are also extremely expensive. Limiting the cable distance to an absolute minimum is therefore desirable. The possible injection points close to the shore are Slijkens or in the harbour of Zeebrugge, both at $150 \mathrm{kV}$. Landing in Koksijde would have a similar effect on the flows as in Slijkens as it is on the same line, but further from the wind farms. Further inland there is a possibility to connect to the substation of Brugge $(150 \mathrm{kV})$, with more redundant connections towards other points in the grid. The nearest $380 \mathrm{kV}$ station is Eeklo-Noord, which is nearly $30 \mathrm{~km}$ inland. Although overhead lines can be used for land connections, the permitting process is long and tedious, with an uncertain outcome.

The remainder of this paper is organised as follows. In section II the investment model is described and calibrated. Base case results for the belgian transmission grid and $2 \mathrm{GW}$ of offshore wind power are derived using the model in Section III. Alternative scenarios for wind power connection are proposed in Section IV. Section V concludes the paper.

\section{MODEL DESCRIPTION}

\section{A. Formulation of the algorithm}

An extended Optimal Power Flow (OPF) approach based on [1] is used to assess the impact of offshore wind power on grid investments. A DC OPF algorithm expanded with transmission investment costs are the core elements. Instead of minimizing generation cost, the sum of generation cost and an annuitized investment cost of the grid is minimized. Not only generation dispatch, but also the ratings of the different lines in the grid are the result of the decision variables. One can understand the proposed problem as given a generation park and the existing rights of way between different nodes, which lines should be built and how should generation be dispatched. The basic linear optimization model is as follows:

$$
\min \left\{\sum_{p}^{n_{p}} \sum_{g}^{n_{g}} c_{g, p} P_{p, g, \text { generated }}+\sum_{l}^{n_{l}} c_{l} \text { length }_{l} \text { rating }_{l}\right\}
$$

s.t.

$$
\forall p, l: \quad\left|P T D F .\left(P_{g}-P_{l}\right)\right| \leq \text { rating }_{l}
$$




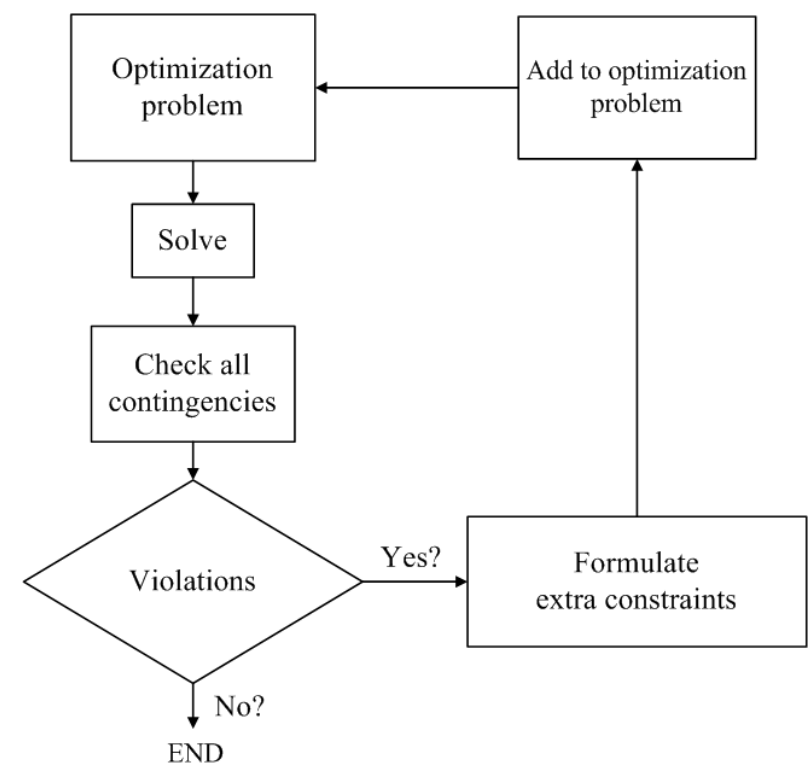

Fig. 3. Flowchart for contingency analysis

$$
\begin{gathered}
\forall p, g: \quad 0 \leq P_{p, g, \text { generated }} \leq P_{g, \text { rating }} \\
\forall p: \quad \sum_{b}^{n_{b}}\left(P_{g}-P_{l}\right)=0 \\
\forall p, b: \quad \text { demand }_{b}=\text { constant } \\
\forall l: \quad \text { rating }_{l} \geq \text { existing rating }
\end{gathered}
$$

$n_{p}, n_{g}, n_{l}$ and $n_{b}$ are respectively the number of time periods, generators, lines and busses. $c_{p, g}$ and $c_{l}$ are generating and line costs. $P_{g}$ and $P_{l}$ are respectively generation and load. The network representation and the resulting power flows use the DC approximation based on power transfer distribution factors (PTDF).

The algorithm optimizes the problem over different time periods $p$. Demand is assumed to be constant, but generation varies over time. In this way wind power can be modeled properly (see also Section II-C).

With this formulation the algorithm decides between reinforcing the existing transmission lines towards cheaper generation (e.g. wind power installed offshore) and dispatching relatively more expensive generation which is connected strongly to the transmission grid and therefore requiring less grid investments. Note that the model assumes continuous variables, whereas in reality variables are discrete (e.g. due to available voltage levels or ratings).

Extra constraints are added to the above formulation to ensure the electricity system is operated $\mathrm{N}-1$ secure. When the base case is solved, possible contingencies (only outages of transmission lines on $150 \mathrm{kV}$ and above in Belgium are considered - the loss of a node, generation unit or foreign line is not considered) are checked. For each possible contingency a power flow is carried out. If the flow over certain lines violates the rated capacity, an extra constraint is formulated (see equation 7 - subscript $c$ denotes contingency) and added to the optimization problem. Figure 3 summarizes the algorithm in a flowchart.
TABLE II

LINE COSTS

\begin{tabular}{cc}
\hline Voltage level & Line costs $(€ / M W \cdot \mathrm{km} \cdot$ year $)$ \\
\hline 380 & 28 \\
220 & 53 \\
150 & 100 \\
70 & 250 \\
\hline
\end{tabular}

TABLE III

WIND POWER DURATION CURVE

\begin{tabular}{ccc}
\hline Period & Duration (h) & Output \\
\hline 1 & 1000 & $100 \%$ \\
2 & 3000 & $75 \%$ \\
3 & 3000 & $30 \%$ \\
4 & 1760 & $5 \%$ \\
\hline
\end{tabular}

$$
\forall p, l_{c}: \quad\left|P T D F_{c} .\left(P_{g}-P_{l}\right)\right| \leq \text { rating }_{l}
$$

The algorithm is implemented in MATLAB and uses the CPLEX solver of TOMLAB for the optimization. PTDF matrices are calculated using MATPOWER [7].

\section{B. Implementation of data}

The Belgian 70-380 kV high-voltage grid and a simplified representation of the surrounding countries is modeled using more than 700 nodes and 1300 lines. Belgian total load is set inelastically at $12.5 \mathrm{GW}$, which corresponds to a high load situation. In the base case Belgium imports about $2 \mathrm{GW}$ from France and exports about $1 \mathrm{GW}$ to the Netherlands.

1) Generation costs: The modeled Belgian generation park consists of over 50 generation facilities with differentiated marginal costs expressed in $€ / \mathrm{MWh}$, pumped storage is excluded. The cost varies from $11 € / \mathrm{MWh}$ for nuclear energy, over $30 € / \mathrm{MWh}$ for coal, till $40 € / \mathrm{MWh}$ for gas. Foreign generation parks take into account the generation mix of the countries concerned.

2) Line costs: Transmission line unit costs are annuitized costs expressed in $€ /$ (MW.km.year). The cost depends on the line's thermal rating and length. For each voltage level (70150-220-380 kV) different unit costs apply. 380 and $220 \mathrm{kV}$ unit costs are derived from [4], lower voltages are extrapolations. Voltage levels have to be determined ex ante, the current voltage level of each line in the grid is used in the model. Today's thermal rating of a line makes out a lower bound in the model as it is assumed only line upgrades (at an equal voltage level) are possible.

3) Wind: To assess the impact of wind power four periods are considered. In each period the wind power output is different representing a wind power duration curve (table III). Load in each bus is equal in each period allowing clear results on the effect of wind power. The foreseen Belgian wind farms are pooled in one node as a $2 \mathrm{GW}$ generator at a distance of $36 \mathrm{~km}$ from the $150 \mathrm{kV}$ onshore connection point in Zeebrugge. Different technology alternatives for grid connection and expansion can be implemented by assigning a different unit cost for the transmission line coming from the wind farm. 
4) Neighbouring countries: Neighbouring countries (the Netherlands, Germany and France) are modeled as a reduced grid with each having their loads and generation. In this way cross-border flows are taken into account. In contrast to the cost of generation in Belgium, where the prices are differentiated over all generation facilities, the cost of generation abroad is constant over all nodes in one country. This price is based on the average generation price.

\section{Calibration}

When this problem is solved without extra wind power generation, it suggests some reinforcements. These reinforcements are also implemented. By doing so, it is assured that the grid model which is started from, is a valid starting point. It can be operated in an economic optimal, and a N-1 safe way. Grid reinforcements suggested afterwards upon adding extra wind generation are due to this extra generation.

\section{BASE CASE RESULTS}

In this section, the results of the optimization problem are discussed. This model is used to investigate which investments are needed in the Belgian transmission grid when $2 \mathrm{GW}$ of wind power is installed in the North Sea. In a first series of simulations the wind is connected in the node Zeebrugge. A thorough analysis is carried out with variations in prices of both onshore and offshore transmission lines. Unless stated otherwise, N-1 security is always enforced in the sense of Section II-A.

\section{A. Offshore cost sensitivity}

The cost of connecting a wind farm to the onshore transmission grid depends on several factors such as technology, voltage level, distance, geography, etc. In the model only two parameters directly influence the cost: distance $(\mathrm{km})$ and the unit connection cost of the wind farm expressed in $€ /(M W . k m$.year). The distance of the wind farm is set fixed at $36 \mathrm{~km}$. It goes beyond the scope of this work to accurately estimate the true connection cost. Therefore a large range is evaluated. Starting from $50 € /(\mathrm{MW} . \mathrm{km}$.year), almost the double of the cost of an onshore $380 \mathrm{kV}$ line, the cost increases till $2000 € /($ MW.km.year).

Testing such a large cost range allows assessing whether it is useful from an economic point of view to connect the nominal power of the wind farm, i.e. $2 \mathrm{GW}$ or only a part of it, e.g. $75 \%$ or even less. As wind power is not fully available at all times, as expressed by the wind power duration curve, a high connection cost might outweigh the benefits of a low-cost or even free source of power. The provided transport capacity should be economically justified and therefore be sufficiently used to be truly profitable [6]. As can be seen in figure 4 it is profitable to connect only $75 \%$ of the wind power output when the unit connection cost exceeds $700 € /(M W . k m$.year).

Additionally, figure 4 illustrates the impact of $\mathrm{N}-1$ constraints in the grid. The maximum cost at which the full capacity of wind park is connected decreases with about $200 € /($ MW.km.year) compared to the case without N-1 constraints.

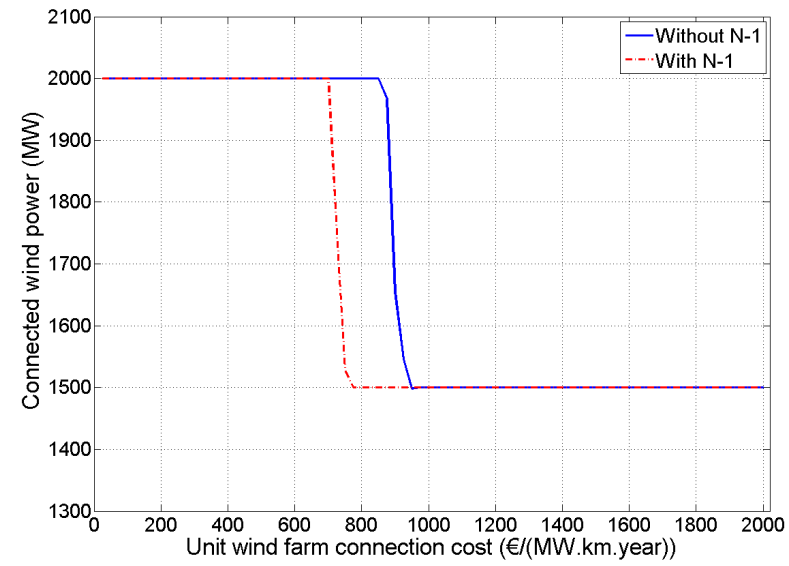

Fig. 4. Connected output of a $2 \mathrm{GW}$ wind farm in Zeebrugge as a function of the connection cost

TABLE IV

LINE RATING CHANGES FOR A LINE COST INCREASE OF 50\%

\begin{tabular}{cccc}
\hline $\begin{array}{c}\text { Connected wind } \\
\text { power }\end{array}$ & $\begin{array}{c}\text { Voltage } \\
\text { level }\end{array}$ & \multicolumn{3}{c}{$\sharp$ lines with a change (MW) } \\
\hline \multirow{3}{*}{$2 \mathrm{GW}$} & $380 \mathrm{kV}$ & 2 & $50 \leq \Delta \leq 100$ \\
\hline & $220 \mathrm{kV}$ & 3 & 1 \\
& $150 \mathrm{kV}$ & 26 & 1 \\
$1.5 \mathrm{GW}$ & $380 \mathrm{kV}$ & 0 & 5 \\
& $220 \mathrm{kV}$ & 3 & 1 \\
& $150 \mathrm{kV}$ & 8 & 0 \\
\hline
\end{tabular}

\section{B. Onshore cost sensitivity}

As the model focuses on transmission investments, transmission cost calibration is important. However, costs vary across regions [4] and due to several other factors such as technology, trajectory, etc. The base case model uses line costs as shown in table II. It is analysed how robust the results are and how the model behaves when these costs vary. Only cost increases are analyzed as this is believed to be the most realistic scenario. When onshore line costs increase with $25 \%$ or $50 \%$ the base case model results barely change. As can be seen in table IV only 38 out of 450 lines (150-220-380 kV) result in capacity change $\leq 100 \mathrm{MW}$ when $2 \mathrm{GW}$ of wind is hosted compared to when standard costs are applied. This number decreases when less wind power is connected to the grid. None of these lines require a change exceeding $100 \mathrm{MW}$. Therefore, the results for onshore line capacities are robust with respect to the transmission line costs.

The onshore line costs do have an impact on the connected wind power of a $2 \mathrm{GW}$ wind farm. Figure 5 clearly illustrates that the maximum cost at which lower than full capacity is connected decreases when onshore line costs increase. The needed grid reinforcements now come at a higher cost. Note that here grid reinforcements for wind power mostly involve $150 \mathrm{kV}$ lines (Section III-C). When these lines are upgraded towards $380 \mathrm{kV}$ (Section IV) the impact is smaller because $380 \mathrm{kV}$ lines have a lower unit cost and are therefore less affected by a cost increase in terms of percentage. 


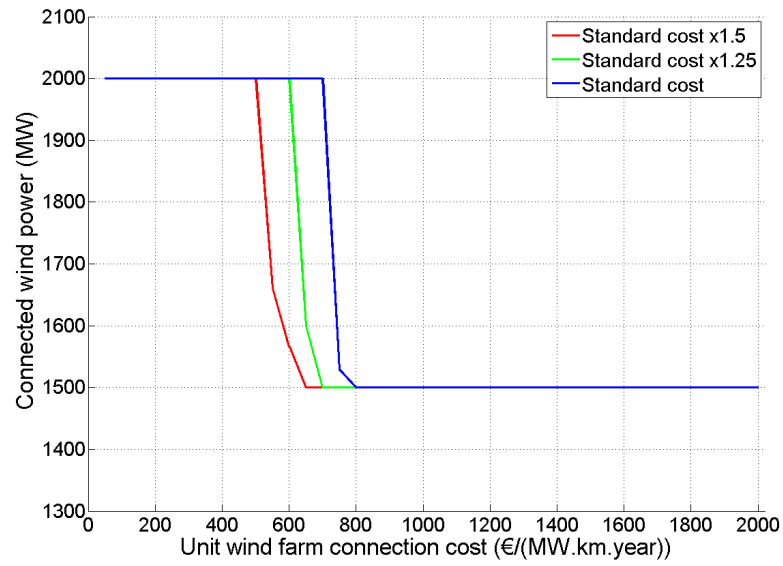

Fig. 5. Impact of higher onshore line costs on connected wind power of a $2 \mathrm{GW}$ wind farm

TABLE V

NUMBER OF LINES (150-220-380 KV) WITH A RATING INCREASE $(\Delta)$ DUE TO OFFSHORE WIND POWER

\begin{tabular}{cc}
\hline & $\sharp$ lines \\
\hline $0 \mathrm{MW} \leq \Delta \leq 200 \mathrm{MW}$ & 11 \\
$200 \mathrm{MW} \leq \Delta \leq 500 \mathrm{MW}$ & 13 \\
$500 \mathrm{MW} \leq \Delta \leq 1000 \mathrm{MW}$ & 0 \\
$\Delta \geq 1000 \mathrm{MW}$ & 5
\end{tabular}

\section{Required reinforcements}

The result of the base case optimization includes line capacities for all lines in the grid. Comparing these capacities with the results of the calibrated model without wind generation (Section II-C) indicates which lines need to be reinforced. The results in table $\mathrm{V}$ indicate that 5 lines need an upgrade exceeding $1 \mathrm{GW}$ in order to accept $2 \mathrm{GW}$ of wind power. One of these lines is the offshore connection to the wind farm. The remaining lines are $150 \mathrm{kV}$ lines between Zeebrugge and Brugge, i.e. the radial part of the $150 \mathrm{kV}$ grid. Next, 13 lines need an upgrade between 200 and 500 MW. On the one hand, the $150 \mathrm{kV}$ grid surrounding Brugge needs to be reinforced, mainly to establish a solid connection with the $380 \mathrm{kV}$ substation Eeklo-Noord. On the other hand, the $150 \mathrm{kV}$ grid surrounding the generation facilities of Langerbrugge and Rodenhuize need to be reinforced. The reason behind these reinforcement is that those generation plants are chosen by the model as the back-up facilities in case of a limited wind power output. This makes sense when the location of Rodenhuize is taken into account. It is situated in the neighbourhood of Eeklo-Noord and is therefore well-suited to take over from the wind farm without dramatically changing the flow pattern in other parts of the grid.

\section{Alternative Scenarios}

Up till now, only reinforcements of existing grid lines are considered as solutions of the formulated problem. This is inherent to the formulation of the algorithm. Only lines included in the grid data can be upgraded. In this section other possible solutions to connect the extra wind in the North Sea to the main $380 \mathrm{kV}$ transmission grid are explored. In the scenarios described in the following section new lines with a rating of $0 \mathrm{MW}$ are added to the network. The optimization model can choose whether to use these new lines or not.

\section{A. Scenario description}

Three scenarios are considered:

1) Zeebrugge $380 \mathrm{kV}$ : Currently, only $150 \mathrm{kV}$ lines are available in the coastal region, as can be seen in figure 2 . Hence the model reinforces the rating of these lines. However the results of the simulations as well as preliminary studies of the Belgian TSO [3], suggest that an extension of the $380 \mathrm{kV}$ to the coast could be favourable. The default technology option for this extension uses overhead lines but undergrounding is considered as well. Undergrounding a line is implemented in the model by assigning a higher cost per MW.km.year to this part of the grid. In line with [5] cost factors of 3, 5 and 7 times the cost of an overhead solution are used.

2) Coastal ring: A next step towards a robust transmission grid near the coast, could consist of the closing of the $380 \mathrm{kV}$ grid. $380 \mathrm{kV}$ lines would be built from Eeklo-Noord over Zeebrugge and Slijkens, back to Izegem (see figure 2).

3) Antwerp harbour: Public opposition could be met, if the above mentioned grid extensions would be built. Therefore another option is considered. In this option, as much wind generation as considered feasible today is connected via the existing grid infrastructure at the Belgian coast. The Belgian TSO states that it is able to host $600 \mathrm{MW}$ of wind power at the coast without major grid extensions. Extra wind generation, i.e. $1400 \mathrm{MW}$, is connected via a HVDC cable in the $380 \mathrm{kV}$ substation Zandvliet (near Antwerp). The HVDC cable can be placed via the river Scheldt. The harbour of Antwerp is a heavy load center and is thus a logic point to connect new generation. It is also well connected to the $380 \mathrm{kV}$ grid. Note, however, that this scenario implies cooperation with the Netherlands, as the estuary of the Scheldt is located in the Netherlands.

\section{B. Offshore cost sensitivity}

For the above described scenarios offshore line cost sensitivity is tested. From figure 2 it is clear that the cost at which less than the full $2 \mathrm{GW}$ is connected is almost the same in the Zeebrugge $380 \mathrm{kV}$ (overhead line) and Coastal Ring scenarios. Other advantages of such a ring such having a more robust $380 \mathrm{kV}$ backbone and the impact on electrical losses are not shown by this model.

The extra cost of undergrounding the proposed new onshore $380 \mathrm{kV}$ lines between Zeebrugge and Eeklo shifts the curve to right. When an overhead solution is chosen (Zeebrugge OHL) the full wind farm capacity is hosted until a connection cost of about $950 € /$ (MW.km.year) whereas the maximal connection cost in case of an underground solution is lower, down to $800 € /$ (MW.km.year) when undergound cables are 7 times more expensive than overhead lines (Zeebrugge UG7).

In the Antwerp harbour scenario, where at maximum $600 \mathrm{MW}$ is connected at the coast and $1400 \mathrm{MW}$ directly to the $380 \mathrm{kV}$ grid in the harbour down the river Scheldt, the connected wind power in the harbour (Antwerp (Harbour)) drops to $1050 \mathrm{MW}$ (or 75\%) when the connection costs 


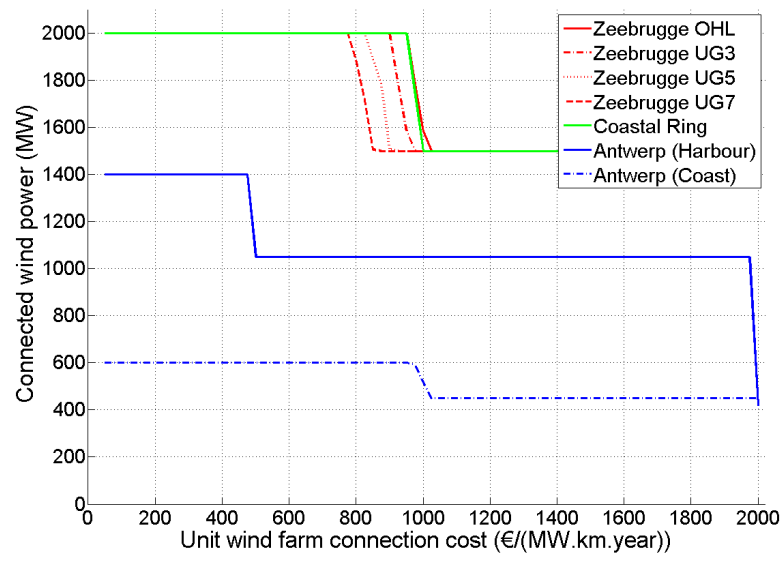

Fig. 6. Connected wind power of a $2 \mathrm{GW}$ offshore wind farm in function as a function of the connection cost for different scenarios

TABLE VI

ZEEBRUGGE $380 \mathrm{KV}$ : NUMBER OF LINES REQUIRING AN UPGRADE $\geq 200 M W$

\begin{tabular}{ccccc}
\hline Voltage level & \multicolumn{4}{c}{ Wind power connection cost } \\
& \multicolumn{4}{c}{$(M W \cdot k m \cdot$ year $)$} \\
& 50 & 950 & 1000 & 2000 \\
\hline $380 \mathrm{kV}$ (Eeklo-Zeebrugge) & 7 & 7 & 7 & 7 \\
$380 \mathrm{kV}$ (Other) & 0 & 0 & 0 & 0 \\
$220 \mathrm{kV}$ & 0 & 0 & 0 & 0 \\
$150 \mathrm{kV}$ & 6 & 6 & 3 & 3 \\
\hline
\end{tabular}

exceeds $500 € /($ MW.km.year). This decrease in connected wind power comes at lower cost than for other scenarios. This is due to the longer distance from the wind farm to the harbour compared to the distance to the coast, respectively $80 \mathrm{~km}$ and $36 \mathrm{~km}$.

\section{Required grid reinforcements}

The required number of lines at each voltage level newly built or upgraded with at least $200 \mathrm{MW}$ in each scenario is given in tables VI, VII and VIII. Zeebrugge 380 and Coastal Ring obviously require a lot of new $380 \mathrm{kV}$ lines (or underground cables). Together this is about $45 \mathrm{~km}$ of doublecircuit $150 \mathrm{kV}$ lines that has to be upgraded to $380 \mathrm{kV}$ and the single circuit line between Zomergem and Eeklo has to be expanded with a second circuit in the case of Zeebrugge 380 (7 different connections in the model). The Coastal Ring scenario implies an additional $55 \mathrm{~km}$ double circuit $380 \mathrm{kV}$ lines (4 lines in the model). For reasons explained above also the $150 \mathrm{kV}$ grid surrounding Rodenhuize and Langerbrugge requires reinforcements.

Although the Antwerp Harbour scenario requires more offshore investments, especially the $80 \mathrm{~km}$ through the river Scheldt, the onshore investments are limited to $2150 \mathrm{kV}$ lines at Rodenhuize. Although the direct investment cost in this scenario can be higher it has clear advantages with respect to possible public opposition.
TABLE VII

COASTAL RING: NUMBER OF LINES REQUIRING AN UPGRADE $\geq 200 M W$

\begin{tabular}{ccccc}
\hline Voltage level & \multicolumn{4}{c}{ Wind power connection cost } \\
& \multicolumn{3}{c}{$\in /(M W \cdot \mathrm{km} \cdot$ year $)$} \\
& 50 & 975 & 1000 & 2000 \\
\hline $380 \mathrm{kV}$ (Coastal Ring) & 11 & 11 & 11 & 11 \\
$380 \mathrm{kV}$ (Other) & 0 & 0 & 0 & 0 \\
$220 \mathrm{kV}$ & 0 & 0 & 0 & 0 \\
$150 \mathrm{kV}$ & 6 & 6 & 1 & 1 \\
\hline
\end{tabular}

TABLE VIII

ANTWERP HARBOUR: NUMBER OF LINES REQUIRING AN UPGRADE $\geq 200 M W$

\begin{tabular}{ccccccccc}
\hline $\begin{array}{c}\text { Voltage } \\
\text { level }\end{array}$ & \multicolumn{7}{c}{$\begin{array}{c}\text { Wind power connection cost } \\
\in /(M W \cdot \mathrm{km} \cdot \text { year })\end{array}$} \\
& 50 & 300 & 500 & 975 & 1000 & 1025 & 1975 & 2000 \\
\hline $380 \mathrm{kV}$ & 0 & 0 & 0 & 0 & 0 & 0 & 0 & 0 \\
$220 \mathrm{kV}$ & 0 & 0 & 0 & 0 & 0 & 0 & 0 & 0 \\
$150 \mathrm{kV}$ & 2 & 2 & 2 & 2 & 2 & 1 & 1 & 1 \\
\hline
\end{tabular}

\section{CONCLUSION}

In this paper an extended DC OPF optimization model based on [1] is proposed to analyze required transmission investments. Within the limits of the model, it allows to investigate the trade-off between the cost of the generation dispatch and grid investments. Especially in a context of public opposition towards new transmission infrastructure this tradeoff has to be carefully examined.

The model is applied on a detailed representation of the Belgian transmission grid in order to determine the required grid investments when $2 \mathrm{GW}$ of wind power is installed in the Belgian coastal waters. The results indicate that when the connection costs increases it is not economic anymore to connect the rated capacity of the wind farm. Major grid investments involving new lines at $380 \mathrm{kV}$ are needed to support the offshore wind power. Additionaly, alternative scenarios are analyzed using the model. A solution where connecting a share of the wind power via the Antwerp harbour allows to limit the onshore grid reinforcements significantly, but this scenario comes at a higher cost with respect to the direct grid connection of the wind farm itself.

\section{REFERENCES}

[1] Kirschen D., Strbac G., Fundamentals of Power System Economics, Chapter 8, John Wiley \& Sons, Ltd, 2004

[2] European Wind Energy Association (EWEA), http://www.ewea.org/

[3] Elia, Federaal ontwikkelingsplan 2005-2012: Bijlagen, 17 September 2005, Avialable online: http://www.elia.be

[4] ICF Consulting, Unit costs of constructing new transmission assets at $380 \mathrm{kV}$ within the European Union, Norway and Switzerland, Final Report, October 2002, Avialable online: http://ec.europa.eu/energy/studies/ index en.htm

[5] ICF Consulting, Overview of the potential for undergrounding the electricity networks in Europe, Final Report, February 2003, Avialable online: http://ec.europa.eu/energy/studies/index_en.htm

[6] Bekaert D., Buijs P., Meeus L., Delarue E. and Belmans R., European energy policy goals: rivals or friends in transmission?, UPEC2008, Padova, Italy, September 1-4, 2008

[7] Zimmerman R., Murillo-Snchez C. E. and Gan D., MATPOWER, http://www.pserc.cornell.edu/matpower/ 